\title{
IETS OVER COLUMBIAANSE EN MEXICAANSE INDIANEN
}

\author{
DOOR
}

\author{
Jhr. L. C. van PanhuYs
}

Professor C. H. de Goeje heeft in de Mei-aflevering een artikel aangekondigd van een zendeling van de orde der Capucijnen, Fray Cesáreo de Armellada in de Venezolaanse te Caracas uitgegeven Zendingsbode van Juni 1948 over een algemeen gevreesde, weinig bekende Indianenstam Los Motilones, die, naar de schrijver zegt, nog niet wetenschappelijk zijn ingedeeld maar stellig niet tot de Caraïben behoren en wier aantal onbekend is, doch niet boven de 2000 uitgaat. Een te Maracaïbo gedrukt verslag van dezelfde Pater van 1943, dat ook door Prof. de Goeje in de laatste Mei-aflevering is besproken, handelt over een van 26 Juni 1943 tot 15 Juli van het genoemde jaar door hem ondernomen onderzoekingstocht, mede in het gebied waar zich ook Motilonen ophouden, namelijk in de Sierra de Perija, tussen het meer van Maracaïbo en de Zuidwestelijk van die stad, maar op zeer grote afstand daarvan, gelegen grens tussen Venezuela en Columbia. Een gebied, zegt de Zendingsbode, zó woest en ontoegankelijk, dat het, hoewel er wel eens een vliegtuig overheen zal zijn gevlogen niettemin aan de beschaafde wereld door zijn afgelegenheid nog meer onbekend is gebleven dan de oppervlakte van de maan.

Toen nu in Juni van dit jaar de oud-secretaris-generaal van het in 1926 te Rome gehouden Americanisten Congres, Prof. Dr. G. V. Callegari, ons een overdruk toezond uit de Handelingen van de Academie voor Landbouw, Wetenschappen en Letterkunde van Verona, Serie V, deel 34, Jaargang 1946-1947, 1949, met op blz. 111 tot 146 een artikel over ,De Vrouw te midden van de grootse beschavingen van vóór-Columbisch Amerika, brachten zowel het geschrift van Dr Callegari als de besprekingen over de Motilones van Prof. de Goeje ons tot een dankbare

$$
-263-
$$


herinnering aan het boek van de Zweedse ontdekkingsreiziger Dr Gustav Bolinder, een rijk geillustreerd prachtwerk van 274 bladzijden groot formaat, handelende over de Indianen in het tropische sneeuwgebergte in het meest noordelijke gebied van Zuid-Amerika, waarin op blz. 203-240 een geheel hoofdstuk aan de Motilonen is gewijd.

Het artikel van Prof. Callegari bevat o.a. een treffende brief van een Indiaanse moeder aan haar dochter. Voorts: Een aan de Amerikaanse schrijver Ch. W. Mead ontleend motto, dat de overgeleverde wijze om een volk te beoordelen moet liggen in een beschouwing van de toestand, waarin de vrouw van dat volk verkeert. Een synthese ten dienste- en tot opwekking van de belangstelling van letterkundigen en studerenden. Een kort begrip van vier voorname beschavingen in de oude Amerikaanse wereld, n.l. van de Nahua's in Mexico, de Maya in MiddenAmerika, de Chibcha in Columbia en de Quechuá-Yanca-Aymará, verenigd onder de Inca's in Peru, Chili, Bolivia en aangrenzende gebieden. Ook nog het slotwoord, dat die volken zeker onze belangstelling en eerbied verdienen.

Het boek van Dr Bolinder toonde op welke wijze deze begaafde Zweed, met twee uitgekozen bedienden, op eerlijke, vertrouwelijke en vriendelijke wijze ontvangen werd door de genoemde Motilonen, zogenaamde Indios bravos, die als wilde dieren in Zuid-Amerika worden gejaagd en neergeschoten, door beschaafden? Ja, àls men ze krijgen kan!

Een Columbiaan, Don Elias Muñoz, verdroot het, dat deze Motilones eeuwen lang hun onafhankelijkheid hadden bewaard. Hij zou ze mores leren. Hij verzamelde zestig gewapende lieden, marcheerde te midden van hen het gebied der Motilonen binnen, en voelde zich zeker. De brallende ,beschaving” tegenover enige, slechts van pijl en boog voorziene, naakte ellendelingen. Maar wat gebeurde? Slechts de hoofden van ten hoogste vijf Motilonen konden af en toe heel even vaag boven struikgewas worden waargenomen. Plotseling viel de heer Muñoz dood neder, door een pijl in 't hart getroffen. De zestig overige beschaafden namen hals over kop de vlucht, maar sleepten het lijk van hun aanvoerder mede.

Hoe handelde Dr Bolinder? Hij had reeds in 1920 met zijn vrouw en dochtertje bij de Ijca-Indianen, eveneens nabij de Sierra Nevada, gewoond. Hij wist met Indianen om te gaan. Had enig bericht, van het verblijf van Dr Bolinder bij de Ijca's, wellicht de Motilonen bereikt? Hoe het zij, hij liet vrouw en doch- 
ter bij de Ijca's achter, en riep, in 't Motilonen-gebied gekomen, met de twee bedienden af en toe zeer luid, om hun bezoek aan te kondigen Ook nu verschenen boven het struikgewas enkele hoofden van de gevreesde ,wilden", die lachende naar hen toekwamen om .... hun bagage te helpen dragen. Hun gezichten, schreef Dr B., drukten slechts vreugde en vriendelijkheid uit.

Toch moet men zich, ook bij vrienden, behoorlijk gedragen. Dr B. zag zich genoodzaakt scherp op zijn beide uitgekozen bedienden te letten. Want sommige van de zeer licht gekleurde, bijna blanke, vrouwen, waren heel mooi en .... hadden maar weinig klederen aan, zodat de fraaie vormen duidelijk uitkwamen en de mannen waren zeer jaloers ......

Overleg met de redactie van De West-Indische Gids leidde tot het vererende verzoek om onder de titel, hierboven vermeld, een overzicht te geven van Prof. Callegari s "Vermaningen", zowel als een uittreksel uit Dr Bolinder s boek.

De opwekking of vermaning (in het Italiaans: esortazione) van een Aztekische moeder aan haar dochter nog vóór de verovering, is te lang om in haar geheel over te nemen. Wij kozen uit wat ons het meeste belang inboezemde. Prof. Callegari verwijst voor bronnenstudie naar de Historia general de las cosas de Nueva España van Padre Sagahun, Mexico 1829-30, p. 380408 en naar de Storia antica del Messico van l'Abate Clavigero, Cesena 1780-1781, Vol. II, pag. 104-109.

Voor een juiste weergave van het authentieke Aztekisch en het oud-Spaans van Sagahun en Clavigero in het Italiaans moeten wij ons verlaten op de encyclopedische kennis van Prof. Callegari, die in zijn rijk werkzaam leven te midden van Mexicaanse Indianen verbleef en arbeidde en nog op hoge leeftijd bezig is met de vertaling van Indiaanse geschriften.

Voor een uitnemende vertaling uit het Italiaans in het Nederlands zijn wij grote dank verschuldigd aan Mevrouw de weduwe J. C. Korthals Altes-Wijnstroom.

Mijn dochter, uit het stof (de materie) geboren, deelgenote van mijn barens-smarten en door mijn melk gevoed. Leg er u op toe altijd goed te zijn. - Het leven is vermoeiend .... maar wees vlijtig in alles. - Wees gereinigd (helder) en span u in om uw huis goed in orde te houden. - Geef uw man met 
eigen handen iedere morgen water en maak het brood voor het huisgezin. - Waar gij u ook heen begeeft, ga met bescheidenheid en zelfverzekerdheid. - Loop niet haastig en lach ook niet tegen degenen, die gij ontmoet. - Laat uw ogen niet lichtvaardig her- en derwaarts dwalen. - Doe aan uw goede naam niet te kort doch beantwoordt beleefd ieders groet of vraag (Ma responda cortesemente a chiunque ti saluta e alcuna cosa demanda). Waak, alzo doende, tegen het toegeven aan slechte gedachten. Antwoordt niet hoogmoedig, toon geen afkeer. - Als gij iets niet vermoogt wat men $\mathrm{u}$ wil opdragen, verontschuldig $\mathrm{u}$ dan op nederige wijze. - Stel $\mathrm{u}$ er niet aan bloot iets te ondernemen wat gij niet kunt. - Bedrieg niemand. - Leef met ieder in vrede. - Indien gij u niet van anderen afkeert, zal niemand zich van u afkeren. - Ga niet zonder noodzaak eens anders huis binnen. - Zo gij de woning van verwanten binnen treedt, groet hen dan eerbiedig bij het binnenkomen. - Zorg, dat niets door uw onachtzaamheid verloren gaat.,

Want uw moeder wenst dat ge in vrede leeft. Als ge mijn raadgevingen niet opvolgt zal het $\mathrm{u}$, door uw eigen schuld, niet welgaan.

Niets meer, mijn dochterlijn. Dat God u voorspoed moge geven.

Dr Bolinder heeft in zijn in 1925 bij Strecker \& Schröder te Stuttgart uitgegeven boek aan 't slot 276 boeken en geschriften aangehaald. Deze litteratuur-opgave is een goudmijn voor ieder student in de Amerikaanse volkenkunde, bovendien een getuigenis van de breedheid van opvatting van dit ook voor leken vruchtbare en goed verstaanbare werk. Het ontbreekt in de Koninklijke Bibliotheek te 's-Gravenhage, alwaar slechts het door Bolinder in 1916 te Stockholm uitgegeven boek in 't Zweeds aanwezig is, welke taal slechts enkele Nederlanders machtig zijn, terwijl daarin de voor studie onmisbare litteratuurlijst niet is opgenomen. Evenmin de 223 opmerkingen voor vakgeleerden en het register van namen en zaken.

Het boek schildert de in 1914/15 en 1920 door Dr Bolinder in de Tairona (Sierra Nevada) en Sierra Perija ondernomen tochten naar de Ijca, Busintana, Kagaba en Motilonen-stammen. Het aangehaalde verslag van Pater de Armadella vermeldt, dat Dr B. in 1937 op nieuw deze streken heeft bezoekt.

Een Engelse stoomboot zette in Februari 1914 de heer en mevrouw Bolinder aan wal in de haven van de in een gloeiend 
hete zandwoestijn gelegen, door zandstormen en muskieten verpeste, vuile en zeer verwaarloosde stad Santa Maria aan de noordelijkste punt van Zuid-Amerika; waar juist karnaval werd gevierd. De bewoners hadden zich daartoe het lichaam en de huizen rijkelijk besprenkeld met de bontste aniline-verven, waarmede ook goedgemeend de voorbijgangers werden besprenkeld.

De arbeidende bevolking leeft er van de kleinhandel en van het loon op de meer landinwaarts, door een Zweed, Bremberg, aangelegde en door de Amerikaanse United Fruit Company beheerde bananen-plantages ${ }^{1}$ ). Mais, rijst en cacao (welke het land overvloedig zou kunnen op leveren, liet men (gemakshalve) uit de Verenigde Staten komen. De prijzen van de levensmiddelen waren zeer hoog. Nadat Dr B. de stad Baranquilla en ook, bij wijze van vooronderzoek, de Ijca-Indianen had bezocht, brak de (eerste) wereldoorlog uit. Brieven en telegrammen hadden twee maanden voor overtocht nodig, en Dr Bolinder werd naar Zweden teruggeroepen. Hij weigerde echter. Liever ging hij met vrouw en pasgeboren dochtertje met zeer bescheiden middelen naar de Indianen, om desnoods onder hen als Indiaan te leven. Liever het kind in het bergklimaat als naar de barre Zweedse winter. Er zou geen geld overblijven voor de terugreis, maar daar zou over moeten worden gepraat. De voorwerpen, die reeds verzameld zijn, worden alvast naar Zweden gezonden (klaarblijkelijk om de chefs gunstig te stemmen) en veertien dagen na de geboorte van het dochtertje ging het gezin per spoor naar Ciénaga, de bananenstad. De hitte was ondragelijk. Wel zijn de sneeuwbergen (boven 5000 M.) op slechts vijf of zes Zweedse mijlen hemelsbreedte afstand, maar het Cesárdal is algeheel ontoegankelijk; slechts langs een zéér grote omweg zijn de Berg-Indianen te benaderen. Er worden 4 muilezels gehuurd. Dr Bolinder draagt te paard de zuigeling in muskietengaas gehuld in een hangmatje om zijn hals. Iedere middag valt de regen in stromen neder, de muskietenplaag is groot: Het drinkwater is zo heet, vuil, modderig en onaangenaam smakend, dat zelfs de bedienden het uitspuwen. De dieren zakken diep in de modder. Bruisende modderstromen worden met levensgevaar overgestoken. De spijs bestaat uit houtachtige gedroogde bananen en bremzoute zeer droge kaas. Het oerwoud geeft verademing, en al zijn de vlakten gloeiend heet, de bodem stijgt. Langs afgronden komt

1) De door Dr B. bezochte plantage besloeg 2800 H.A. en leverde per H.A. 700 bossen van ten hoogste 200 baranen. 
men op $1000 \mathrm{~m}$ hoogte, waar het klimaat verandert en de muskieten wegblijven. In het creolen-dorp Pueblo Viejo ontvangt het gehuwde dorpshoofd hen vriendelijk; hij draagt een reusachtige stroohoed en pantoffels met zilveren sporen. De dienstmaagden zijn, naar 's lands gebruik, tevens zijn bijwijven, die harder moeten werken dan de vrouw zelf. De inwoners planten koffie en maken bruine suiker, panela. De muildieren kunnen niet meer en worden tegen draagossen ingewisseld. De negerbediende begint van kou als een hondje te beven. Nog een hevig onweer en stroomende regen en men bereikt, na een piek van $3000 \mathrm{~m}$ te zijn overgetrokken, in de maneschijn een aantal witte huizen met grauwe daken achter een hoge muur van rolstenen. Het is het dorp van de Ijca Indianen. Het doel is bereikt.

Het dal met de omringende blauw en paars getinte heuvels is overweldigend schoon. Er zijn overal bloemen. IJskoude beken ruisen over wit zand en bont gesteente. Volkomen passen in het landschap de statige Indianen in hun witte mantels, de kleine met gras gedekte hutten en de kudden sneeuwwitte schapen en halfwilde bruine paarden. De zon, wier stralen tot nogtoe angstig werden vermeden, schijnt hier mild en opwekkend. De straten zijn schoon, de dieren zijn buiten het dorp ondergebracht; gezamenlijk zorgt men voor de straatreiniging. De dorpsbodem helt, zodat 't regenwater zó wegstroomt. Nooit behoeft men er, na een bui, kniediep door 't water te waden als in de creolendorpen.

De Ijca's beschermen hun spijzen tegen kakkerlakken. Zij ruiken zelf steeds naar rook; zij zijn schoon en helder en baden ijverig, maar zijn toch behept met hoofdluis. De mannen zijn krachtig gebouwd; hun lichaamslengte is gemiddeld $1.60 \mathrm{~m}$; ; die van de vrouwen $1.50 \mathrm{~m}$. Enkele vrouwen waren boven de 80 , zelfs bijna 90 jaar. In 1915 stierven meer dan 80 Indianen aan van beschaafden overgekregen mazelen. Borstziekten en hoest komen veel voor. Koortslijders worden gedompeld in ijskoud water (Shock?). Muskieten en malaria ontbreken. De temperatuur's nachts is $8-12$ graden. Mais is het hoofdvoedsel, de Ijca drinkt nooit koffie maar gebruikt gaarne zout. Men mag nooit spijs overlaten. Men durfde niet bij Dr Bolinder gaan eten, want het eten moest eens vergiftig (behekst) zijn.

Behalve ingevoerde ijzeren bijlen waren ook stenen bijlen ingebruik. Bij de Ijca's zijn het de vrouwen, die weven, bij de Kagaba's de mannen. De vrouwen zijn steeds met het naaien 
van tassen bezig, zelfs wanneer zij een last of een kind op de rug dragen. Cola-sap wordt gebruikt tegen vermoeienis en honger. Brandewijn is, helaas, het belangrijkste handels- en betaalmiddel met de creolen. Doch in November 1920 nam de missie van de Capucijner monniken vele kinderen aan en de prefect kwam, zeker op hun aansporing, op voor de op de plantages in schuld werkende Indianen; alle brandewijnschulden werden toen geschrapt.

Zonder de flinkheid en practische kennis van moeder de vrouw zou Dr B. het heel moeilijk hebben gehad. Om aan eten te komen moesten dekens worden ingeruild en zakdoeken, die Mevr. B. uit haar mans hemden knipte (die dus hoe langer hoe korter werden). Er was geen goed brandhout, en de was viel Mevr. B. zéér zwaar. Nooit behoefde het echtpaar de hut af te sluiten. De vrouwen juichten, wanneer Mevr. B. haar dochtertje droeg. De Ijca's moest men niet met anthropologische metingen of fotograferen aankomen, en het duurde lang eer zij Dr B. de Ijcataal wilden leren. Mevr. B. vonden zij: ,,zo schoon als kaarslicht”; heur haar moest stellig van goud zijn. Onbeschrijfelijk veel hielden zij van de kleine Sif, en de ouders maakten zij soms midden in de nacht wakker om het dochtertje of het gouden haar van Mevr. B. te mogen zien!

De Indianen zijn vrij van belasting. Monogamie is regel, tenzij de vrouw, wat zelden voorkomt, kinderloos blijft. De liefde voor de kinderen is groot. Indien de regering een ongeschikt vertegenwoordiger benoemt, wordt hij niet gehoorzaamd. Huizenbouw geschiedt gemeenschappelijk. Overtredingen en misdrijven zijn zeldzaam, maar in dronkenschap wordt gevochten. Oude mensen worden levend begraven om iemand tegen zelfmoord te behoeden en hun zo een dienst te bewijzen. Het haar afknippen is een gevoelige (want magische) straf. Onder elkaar zijn zij vrolijk en opgeruimd. Geschillen worden meest door (zeer matige) geldboeten vereffend. Een bedrogen echtgenoot vroeg als vergoeding een oude hen. Toen men hem betoogde, dat hij meer vergoeding had moeten vragen, antwoordde hij ,Och, mijn vrouw was ook niet meer waard".

$\mathrm{Er}$ is (vanzelfsprekend) een zondvloed-legende, eveneens een sage van een lichtgekleurde, baardige Beschavingsbrenger, zoals in Chili en tot de Rio Grande wordt gehoord.

$\mathrm{Bij}$ de medicijn-mannen is vasten een veelvuldige gebruik. Alle Indianen kennen heilkrachtige kruiden. Toen in 1920 Dr B. 
aan een medicijnman vroeg, hoe het met de kinderen in Zweden ging, moest hij de richting van $Z$ weden aanwijzen. De eerste nacht mislukte de poging, maar nadat Dr B. op nieuw de richting had aangewezen, zeide de medicijnman de volgende morgen, dat hij de kinderen gevonden had. Ze waren ziek geweest maar nu weer veel beter. Dr Bolinder schrijft: Later kwam uit, dat hij volkomen gelijk had gehad.

Wij laten de huis-, akker- en gezinsgebruiken, de feesten en dansen buiten beschouwing. Veel is er bij de Ijca's veranderd, sedert de zending zich hun lot heeft aangetrokken. De practische arbeid, die de monniken om het dorp hebben verricht, is geweldig. De kinderen zongen de Bisschop toe, zij zingen uitstekend, maar het waren Latijnse en Spaanse hymnen. Tegen het gevaar van ondergang door toedoen van blanken en creolen zijn zij thans voor goed beveiligd.

Naar de Motilonen ging Dr Bolinder, in 1920 met, zoals gezegd, twee uitgekozen bedienden. Op $1200 \mathrm{M}$. had de reeds beschreven ontmoeting plaats. $\mathrm{Zij}$ werden als lieve famielieleden geliefkoosd, moesten in het nabijgelegen dorp in een van de luchtige hutten op matten zitten en lesten daar hun dorst met koud maïsbier.

De Bisschop heeft (gelukkig) het recht aan onbevoegden de toegang tot hun gebied te verbieden. De Indianen gaven zelfs crediet, en waren met elk ruil aanbod tevreden. Een weefstoel met aangevangen weefsel van een muts werd eerst de volgende dag verkregen: de eigenaar wilde geen onvoltooid werk leveren en zijn vrouw had de gehele nacht moeten weven om de muts gereed te krijgen. In Maraca waren de Indianen gemiddeld $140 \mathrm{~cm}$ lang. Volgens Dr Ronhaar in de Encyclopedie van Winkler Prins (zie Dwergvolken) is $160 \mathrm{~m}$. de grens, voor een dwergvolk. Deze Indianen zijn dus waarlijk dwergen. Zij leven hoofdzakelijk van plantenvoedsel. Men moet hun vlijt en uithoudingsvermogen bewonderen. $\mathrm{Zij}$ tellen tot tien, door telkens een vinger om te buigen.

Helaas kreeg een Motilonen-Indianengroep, de Milagrus, die Dr B. in 1915 bezocht, later een mazelen-epidemie, zodat van 250 Indianen slechts vijf overbleven.

In Januari 1921 verliet de familie Bolinder de dalen van de Maraca's en kwam aan Dr Bolinder's tweede reis in ZuidAmerika een einde. 